\title{
Development of Web-Based Media Repository in P3M State Polytechnic of Bali
}

\author{
I Ketut Suja*, Ni Luh Eka Armoni, Ni Luh Ayu Kartika Yuniastari Sarja \\ Tourism Department \\ Politeknik Negeri Bali \\ Badung, Indonesia \\ *suja@pnb.ac.id, luhekaarmoni@pnb.ac.id, yuniastari@pnb.ac.id
}

\begin{abstract}
Bali State Polytechnic has not provided a repository system facility for online lecturer research results. Planning a web-based repository system for lecturers' research results in PNB is indispensable. In the future, the content of the repository development will be expanded so that the final project and student thesis can be stored in one container. With the Repository System, students can find and read theses online. The stages of development in this system use Model V. Where Model $V$ is the development of the System Development Life Cycle model. Model $\mathrm{V}$ has a branching process. The purpose of this research is to support the dissemination of research results from lecturers and students and to improve the rankings of higher education institutions (Webometrics) so that a repository is created. In addition, to improve repository services, evaluation components of Webometrics' ranking need to be implemented, namely Size, Visibility, Rich files, Scholar, and Altmetrics. The final result of this research is a software repository that can be used as a storage medium for the research results of lecturers and students at Bali State Polytechnic.
\end{abstract}

Keywords—dissemination, digital repository, webometrics

\section{INTRODUCTION}

The development of the repository institution (IR) has attracted the attention of many researchers, academics, universities and research institutions. Based on search results in the Library, Information Science \& Technology Abstracts (LISTA) and Scopus, there are more than 300 articles discussing IR that have been published in various international peer-review journals, spanning from the early 2000s to the present. Apart from being in the form of journal articles, theses and dissertations focusing on studying IR from various universities in the world are also abundant. Hundreds of books, manuals and websites were created and brought in for IR developers. Several international conferences, especially in the field of library and information science, have also raised IR as a major theme. The foregoing can indicate that the importance of developing IR has become a joint conversion [1].

Bali State Polytechnic (PNB) is one of the state universities which consists of 6 departments and 17 study programs, in part of its performance it has utilized the Information System. Apart from information systems, entities within the scope of PNB use the Internet a lot to help its performance. With the increasing number of entities involved, of course it will require better infrastructure.

According to Lynch, a repository is a set of services offered by universities to lecturers / students for the management and dissemination of digital material created by the institution [2]. This is essentially the organization's commitment to the stewardship of digital materials, including long-term preservation and proper organization and access or distribution. Repositories that can be downloaded from outside the institution are generally digital repositories. A digital repository is a mechanism for managing and storing trustworthy digital content, be it subject, institutional or commercial repositories.

Various collections can be included in the digital repository for the user. It is the technical capabilities and administrative policies that decide what types of material go to the repository. Typically, content can include research output such as journal articles or research results, e-theses, E-dissertations, e-Learning objects and teaching materials, as well as administrative data [3]. Furthermore, Shoeb states that some repositories take certain collections such as theses or journal papers as they are collected from any reliable scientific work produced by the institution [3]. Complex objects and other data files are also part of digital content. A digital repository doesn't just require an organized collection of digital content. It also requires that content be accessed and distributed as widely as possible for users around the world. Access management and control is one of the main concerns for content providers on the Internet. Without proper access, and information integrity cannot be guaranteed despite the different methods used by content providers to provide better accessibility to users.

The development of an institutional repository (IR) has become a concern of many researchers, academics, universities and research institutions. Based on search results in the Library, Information Science and Technology Abstracts (LISTA) and Scopus, there are more than 300 articles discussing IR that have been published in various international peer-reviewed journals, spanning from the early 2000s to the present. Apart from being in the form of journal articles, theses 
and dissertations focusing on studying IR from various universities in the world are also abundant [4]. Hundreds of books, manuals and websites have been created dedicated to IR developers. Several international conferences, especially in the field of library and information science, have also raised IR as the grand theme. The foregoing can show that the importance of developing IR has become a common belief. This paper will discuss the definition of an institutional repository; types of repositories other than institutional repositories and their respective characteristics; the relationship between scholarly communication, open access, and the idea of developing an institutional repository; potential collections are stored in the institutional repository; and deposit policy.

Defining Institutional Repository Etymologically, a repository can be interpreted as a place to store (archiving). Meanwhile, institutional means institutions or those owned by institutions (such as universities or other institutions). One of the many cited definitions of IR is that of Lynch. "... the institutional repository is a set of services that a university offers to the members of its community for the management and dissemination of digital materials created by the institution and its community members." 1 In this definition, Lynch emphasized that IR is a series of services. (a set of services) developed by a university (institution) in the form of management and dissemination of various scientific activities of academicians in the form of digital materials [5].

\section{RESEARCH METHOD}

This research aims to produce a repository software, in this case a web-based repository at P3M State Polytechnic of Bali. This is done using the method The V-Model is an SDLC model where the implementation of the process occurs sequentially in the V-shape. Also known as the Verification and Validation model [6-8].

The V-Model is an extension of the waterfall model and is based on the association of the appropriate testing phases for each development stage. This means that for every single phase in the development cycle, there is a directly related testing phase. This is a very disciplined model and the next stage starts after the completion of the previous stage.

In stage of Model $\mathrm{V}$, programming is carried out for each module that has been formed, which is a sequential and systematic software development method [9] which consists of stages, namely: Requirement Analysis \& Acceptance Testing, System Design \& System Testing, Architecture Design \& Integration Testing, Module Design \& Unit Testing, Coding.

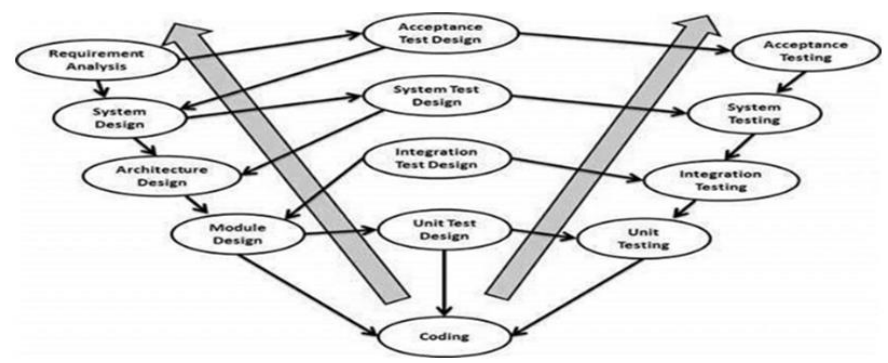

Fig. 1. The various stages in the V-Model SDLC.

At the analysis stage, the process of gathering software requirements, such as the information domain, performance, and required interfaces, is carried out. This stage will produce a software requirement specification that is presented in the form of a data model in the form of an ERD (Entity Relationship Diagram), a process model in DFD (Data Flow Diagram) and a transition model in the form of STD (State Transition Diagram). This article only focuses on the final results of research in the form of software products, so the results at the analysis stage are not presented in this article.

The design is a multi-step process that follows up on the results of the analysis phase, consisting of data design in the form of database structure design, architectural design in the form of program structure design, interface design and procedural / algorithm details that will be applied in the next step.

Encoding is the process of translating a design into program code that can be read and performed by a computer machine. In this case the coding will be used using the PHP Triad program which consists of the PHP programming language, MySQL database and Apache server [10]. This stage realizes the results of analysis and design in the form of software products and these stages are presented in this article.

Testing is the stage of creating code which consists of testing internal logic and external functional testing to find errors and ensure the results are as needed. Testing is carried out internally by the developer with results as shown in this article.

\section{RESULT AND DISCUSSION}

This Web-based repository system application software development uses the PHP Triad program which consists of the PHP programming language, MySQL database and Apache server [9]. Apart from that, Dreamweaver support software is also used to help create the user interface. The coding results are as follows:

\section{A. Login Repository}

As a prefix to being able to use Bali State Polytechnic, what you have to do is type the URL address http://repository.pnb.ac.id in the browser can be seen in Fig. 2 . 


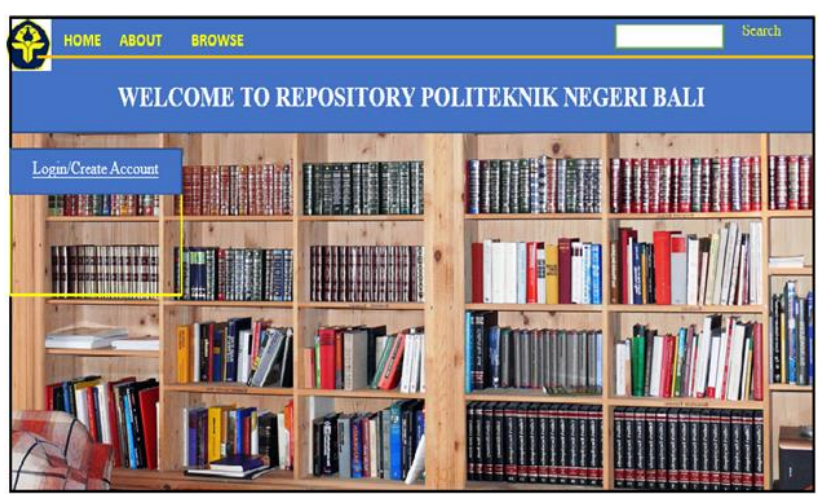

Fig. 2. Repository main page.

From that screen, click on "Login" at the top left of the main menu display, and then you will see a screen like in Fig 3. In that screen, type your Username and Password, then click Login, and the display that will appear is the manage deposit view.

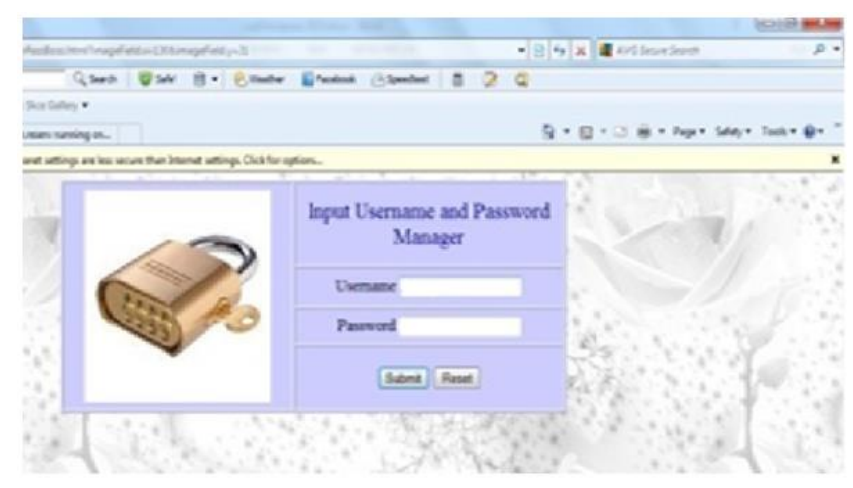

Fig. 3. The repository login page.

\section{B. Procces Entri Repository}

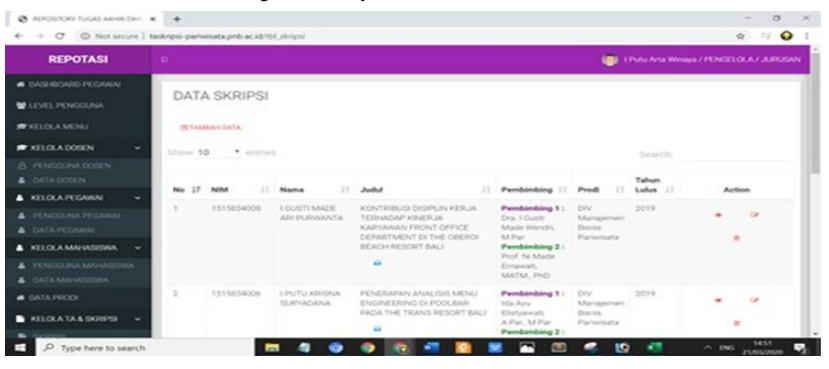

Fig. 4. Procces entri repository (1).

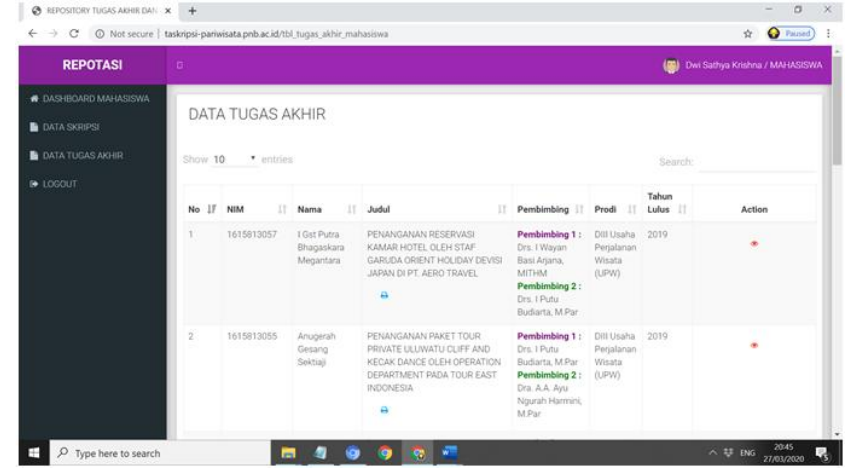

Fig. 5. Procces entri repository (2).

The stage that functions for the entry of the material to be uploaded. The material is in the form of files containing manuscripts, scientific paper documents, theses, research, theses, and so on, which can be in the form of formats, images, videos, audio, and others.

\section{Edit Uploaded Items - Repository}

On this page you take the file to be entered, by clicking on Browse, clicking on the file name of your document, clicking Upload, then clicking Next.

\section{Edit Item Details - Repository}

The detail page is the process of entering the details of the previously uploaded file. In this detail tab, there are many fields that provide details on the file. Each file type has a different field, but make sure you fill in the fields that have an asterisk so that the file can be processed to the next process. At this stage, it is the process of filling in the details of the file you are entering.

Details: Title (Filled with the title of the article or file), Abstract (Filled with an abstract of the article), Creators (Filled with the name of the author, Corporate Creators (Filled with agencies, Divisions (Click on the appropriate faculty and study program options) and Publication Details (In this section, each item type has a different field but what must be filled is an asterisk to be able to proceed to the next stage. For other columns it functions as complementary data.)

\section{E. Edit the Subject - Repository item}

Click on Add according to your article category. You can choose more than 1 subject for categorization according to the content or discussion in the article or file that you upload. Next, click Next.

\section{F. Deposit Item Files - Repository}

Deposit Item Now, on Move to Repository: To see the results of the entry process), Summary (To see the title, abstract, and other parts of the uploaded file which are called metadata 


\section{CONCLUSION}

Based on the research that has been conducted by the author, several conclusions can be obtained, including: 1) that this final project repository system makes it easy for students and lecturers to upload research results, theses and TA. 2) The P3M Bali State Polytechnic repository application functions as a digital library, can be used as a thesis search facility and thesis download online and makes it easier for students to search for thesis references

\section{ACKNOWLEDGMENT}

The author would like to thank profusely to P3M Bali State Polytechnic for their support in this research unnumbered footnote on the first page.

\section{REFERENCES}

[1] G. Eason, B. Noble and I.N. Sneddon, "On certain integrals of LipschitzHankel type involving products of Bessel functions," Philosophical Transactions of the Royal Society of London. Series A, Mathematical and Physical Sciences, vol. 247, no. 935, pp. 529-551, 1955.
[2] K. Arlitsch and S.O. Patrick, "Invisible Institutional Repositories: Addressing the Low Indexing Ratios of IRs in Google Scholar," Library Hi Tech, vol. 30, no. 1, pp. 60-81, 2012.

[3] M. Amstrong, Institutional repository management models that support faculty research dissemination [Online]. Retrieved from: www.emeraldinsight.com/1065075X.htm, Accessed on 10 August 2020

[4] Z.H. Shoeb, "Access Management for Digital Repository DESIDOC," Joumal of Library \&Information Technology, vol. 29, no. 4, pp. 21- 27, 2020

[5] C. Armbruster and L. Romary, "Comparing repository types: challenges and barriers for subject-based repositories, research repositories, national repository systems and institutional repositories in serving scholarly communication," International Journal of Digital Library Systems (IJDLS), vol. 1, no. 4, pp. 61-73, 2010

[6] C.A. Lynch, "Institutional repositories: essential infrastructure for scholarship in the digital age," portal: Libraries and the Academy, vol. 3 , no. 2, pp. 327-336, 2003.

[7] S. Sutarman, Building Web Applications with PHP and MySQL Yogyakarta: Publisher Grahallmu, 2003.

[8] E.H. William and L. David, Web Database Application with PHP and MySQL. O'Rilly and Associates Inc, 2012.

[9] P. Pressman, Software Engineering, $7^{\text {th }}$ Edition. McGraw-Hill International Inc, 2015.

[10] B. Nugroho, Exercise Create PHP and MySQL Web Applications with Dreamweaver MX. Yogyakarta: Gava Media. 8th ed, 2008. 